\title{
Jean-Marie Seillan, Huysmans et les censeurs
}

\section{Erica Tacchino}

\section{(2) OpenEdition}

\section{Journals}

\section{Edizione digitale}

URL: https://journals.openedition.org/studifrancesi/46179

DOI: 10.4000/studifrancesi.46179

ISSN: 2427-5856

\section{Editore}

Rosenberg \& Sellier

\section{Edizione cartacea}

Data di pubblicazione: 1 octobre 2007

Paginazione: 471

ISSN: 0039-2944

\section{Notizia bibliografica digitale}

Erica Tacchino, «Jean-Marie Seillan, Huysmans et les censeurs», Studi Francesi [Online], 152 (LI | II) | 2007, online dal 30 novembre 2015, consultato il 24 novembre 2021. URL: http://

journals.openedition.org/studifrancesi/46179; DOI: https://doi.org/10.4000/studifrancesi.46179

Questo documento è stato generato automaticamente il 24 novembre 2021.

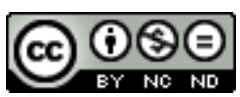

Studi Francesi è distribuita con Licenza Creative Commons Attribuzione - Non commerciale - Non opere derivate 4.0 Internazionale. 


\title{
Jean-Marie Seillan, Huysmans et les
} censeurs

\author{
Erica Tacchino
}




\section{NOTIZIA}

JEAN-MARIE SEILLAN, Huysmans et les censeurs, «Revue d'Histoire Littéraire de la France», janvier 2006, 106e année, n. 1, pp. 83-115.

1 Nel presente articolo il critico svolge una minuziosa analisi sul comportamento di Huysmans di fronte alla censura per dimostrarne il carattere contraddittorio. Infatti, nel 1898, anno di pubblicazione di La Cathédrale, l'autore sceglie di autocensurarsi per timore che la sua opera venga iscritta all'Index a causa del suo atteggiamento ostile verso i dettami della Chiesa Cattolica, così pubblica il libro, insieme a En Route (1895), in un'edizione purgata sotto il titolo di Pages Catholiques (1900).

2 Al contrario, nel 1904, resiste all'attacco che gli viene sferrato dai giornali, soprattutto dalla rivista cattolica Le Correspondant, che intende fargli rinnegare e censurare gli scritti pubblicati prima dell'inizio della sua fase credente (in particolare la prefazione di À Rebours, 1884).

3 Contemporaneamente, però, procede alla raccolta delle poesie cristiane di Verlaine, raccogliendole sotto il titolo di Poésies Religieuses.

4 Jean-Marie Seillan si domanda la ragione del comportamento incoerente di Huysmans, e sostiene che lo scrittore agisca consapevolmente in questo modo perché intende "attaccare" indirettamente il clero stesso entrandovene a far parte.

Infine, il critico afferma che è proprio grazie alla sua ambiguità che l'autore di À Rebours giunse a essere rispettato all'interno della Chiesa, pur senza rinnegare l'amicizia con i poeti maledetti, così riuscendosi a collocare in una posizione mai troppo scomoda ed estrema. 